\title{
THE INCIDENCE OF SEPSIS IN INDUSTRIAL WOUNDS
}

BY

\author{
R. E. O. WILliaMS AND E. H. CAPEL
}

\author{
From the Medical Research Council Wound Infection Unit, Birmingham Accident Hospital, and the Medical \\ Department, Joseph Lucas Limited, Birmingham
}

In this paper we report an investigation of the prevalence of sepsis among the workers in an engineering factory, and attempt to estimate the risk of sepsis in the wounds inflicted there.

Official figures for sepsis in a selected group, namely reportable accidents (i.e. those resulting in more than three days' absence from work), are collected by H.M. Inspector of Factories and they have been discussed by Henry (1943). These figures do not, however, directly measure the incidence of sepsis in wounds, since the number of cases reported as septic is set against the total number of reportable accidents, which includes not only wounds but also eye injuries and closed injuries (hernia, closed fractures, muscle strains, etc.) which are not at risk for the development of sepsis. Furthermore, the figures do not include wounds, serious enough to lead to absence from work from the day of injury, that become septic after notification. The official sepsis rate, therefore, gives the number of workers who are put off work on account of sepsis that is already present at the time of notification, and not the total number whose wounds become septic, nor the number whose return to work is delayed by sepsis. Septic wounds that do not lead to four days' absence from work are not included at all.

To demonstrate the implications of the published figures we have analysed the records for 1944 from one factory engaged in light engineering and employing an average of 7430 workers. The inquiry cannot readily be extended to other factories, because it is made possible, in this case, by a relatively rare combination of circumstances: the medical department keeps record cards for each individual attending the surgery, so that the history of each wound is traceable; almost all the wounds that require hospital treatment are sent to one hospital (the Birmingham Accident Hospital) where their records are again available; and we have the data gathered in a close clinical and bacteriological study of some 280 of the wounds treated in the surgery of the same factory in autumn of 1943 (the factory A of Clayton-Cooper and Williams, 1945).

\section{Reportable Accidents}

During 1944, 266 accidents led to more than three days' lost time (Table 1). The 'sepsis rate,' as calculated by the Factory Inspectorate, was 27.4 per cent., i.e. 73 of the 266 workers were put off work on account of sepsis. However, 123 of the 266 workers had no open wound. Of the remaining 143, 73 (51 per cent.) had septic lesions, in most cases probably arising from trivial wounds (see below) which would not have led to loss of time unless the sepsis had developed; and 63 had wounds which were not septic but were severe enough to lead to absence from work from the day of injury. The notes of the remaining seven patients could not be traced.

\section{TABLE 1}

\section{ANALYSIS OF ACCIDENTS REPORTED IN 1944}

(a) Total number of accidents reported to Factory Inspectorate . . $\quad$. . $\quad$.. 266

(b) Number of accidents reported as 'septic' 73

(c) Number reported as 'clean wounds' . . 63

(d) Number of accidents not resulting in wounds (eye injuries, closed fractures, sprains, hernia, etc.) $\quad . \quad \quad \ldots \quad$..

(e) Wounds, notes not traceable .. . .

(f) Percentage of all accidents (a) reported as 'septic' .. .. . .. . ..

(g) Percentage of accidents other than those in group (d) reported as septic .. . .

(h) Number of wounds in group (c) that developed sepsis after reporting $\ldots$

(i) I.e. total number of wounds septic at some

(j) Total percentage of all reported accidents (a) that were septic at some time $\ldots$

(k) Total percentage of accidents other than
those in group (d) that were septic ..

Sepsis may develop in a wound while it is under treatment at the surgery, or it may develop in a hitherto untreated wound and induce the worker to attend the surgery. Further analysis of the factory records shows that, of the 73 wounds reported as septic, 66 (90 per cent.) were already septic when they were first seen at the surgery, and only seven had become septic, and therefore reportable, while under treatment. Eight of the 63 initially clean serious wounds later developed sepsis.

\section{Non-reportable Accidents}

If, instead of studying the reportable accidents, we turn to the data for all the wounds presented to the factory surgery, we obtain very similar proportions (Table 2). In 1944, there were 8101 first attendances at the surgery by workers with cuts, burns, abrasions, etc.; of these 1050 (13 per cent.) were already septic at this first attendance. Inquiry of 230 randomly selected patients attending the surgery with such septic lesions revealed that in 76.5 per cent. the lesion had arisen from a trivial 
wound which the patient had noticed at the time of injury, but for which he did not then have treatment; some sign of an antecedent injury was visible in a further 13.5 per cent.

\section{TABLE 2}

ANALYSIS OF SURGERY RECORDS FOR 1944

Total attendances at surgery with cuts, burns,

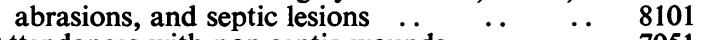
Attendances with non-septic wounds $\quad \ldots .6707$ Attendances with lesions septic at first attendance $\quad 1050$ Estimated number of initially clean wounds that became septic before healing ( 5 per cent. of total)

Clayton-Cooper and Williams (1945) found that the incidence of sepsis developing in initially clean wounds attending the surgery (in the autumn of 1943) was in the region of 5 per cent. The incidence is unlikely to have risen since, and may well have fallen, because in the interval a number of improvements were made in the surgery routine. If, however, we take the figure of 5 per cent. to be applicable to the 7051 fresh wounds seen at the surgery in 1944, we would expect 353 to have become septic under treatment; in fact we note that approximately three times as many wounds as this (1050) were observed to come to the surgery already septic.

Studying the proportions of septic and clean wounds that would be recorded by the Factory Inspectorate because they led to loss of time, there is the same excess in the percentage of wounds septic when first seen over the percentage becoming septic while under treatment. Of 7051 workers with wounds seen at the surgery soon after the injury $63(0.9$ per cent.) had to be put off work immediately, and a further seven $(0 \cdot 1$ per cent.) were put off later because severe sepsis developed in the wound while it was under treatment. Thus 1 per cent. of the workers with wounds presented to the surgery at the time of injury were put off work at some time. On the other hand, of the 1050 workers with wounds that were septic when first seen, 6.3 per cent. (66) were off work more than three days; this proportion is more than six times that for the clean wounds.

\section{Untreated Wounds}

The facts presented suggest that the workers were, in many instances, failing to attend the surgery with small cuts unless the development of sepsis in the wound made attendance necessary, and it seemed desirable to attempt to estimate the risk of sepsis in the trivial untreated wounds. At Professor Bradford Hill's suggestion we accordingly tried to make a count of all the wounds inflicted in the factory on one day.

A questionary form (fig. 1) was given to each charge-hand (responsible for 10-30 workers) and he was told of the aim of the investigation and the method of completing the form; we defined an injury as any lesion that drew blood from the skin. Thinking that some workers might fail to report injuries if they thought that disciplinary action would be taken against those who had not obeyed the standing rule to present all injuries for treatment, we did not ask for names or check numbers. The questionary was completed in the last halfhour of the day's work, each worker reporting the number of injuries sustained in the day. Owing to the administrative structure of the factory, it was possible to survey only 'production workers,' i.e. those directly concerned with production and not the maintenance and office staff, whose injuries contributed to the totals given in Table 2 . From

UIEDICAL DEPARTMENT - JOSEPB LUCAS LED.

\section{IXPORTAIT}

In connection with the investigations being carried out by The Modicel Research Council on the prevention and treatmont of a count of all injuries, serious or trivial, ocourring on one particular day.

Th1s form 1s belng 18sued to all charge-hands, who are asked Th1s form 18 belng 18sued to all charge-hands, who
to carry out the following ingtruet1 ons acouratoiy.

\section{Instructions.}

1. Vo1ng a separate square for each rorker fill in the number of the singio dov.

2. If a worker oustains no injarios put 0 . Th1s 18 most Important.

3. Take the count during the last half hour of the day' 8 work.

4. Return the form 1mmediately to your auperintendent. Department $\ldots \ldots \ldots \ldots \ldots \ldots \ldots \ldots \ldots$

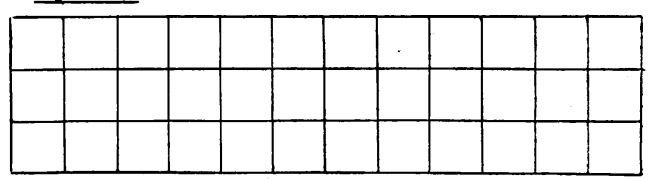

Read the following notes:-

Count all in jurtes, however triv1al, sustainod at work

It does not matter whether tho injury was treated or not. count it.

Don't Porget to count yourself.

Th1s investigation 18 concerned with research into means of prevention and treatment only. Ho nemes or cheor number

FIG. 1.-Questionary form used for census of injuries.

fear of causing too great a loss of working time, we have only taken two counts at the factory from which we gathered our main data, but comparable investigations have been carried out in two similar factories. We have estimated the risk of sepsis in the wounds by relating the daily number of untreated wounds, derived from the census, to the average daily number of wounds presented to the surgery already septic, on the assumption that the great majority of the latter arise from trivial wounds not treated on the day of injury.

With the many limitations, and with the additional difficulties that many of the smallest wounds may not be noticed by the worker, and that some of the septic lesions certainly do not arise from wounds such as are counted in the census, it is evident that our results can give only the very broadest indication of the rate of wounding and the risk of sepsis. Nevertheless, we feel that they do enable us to get a clearer idea than was previously possible of the risk of sepsis in small untreated wounds. 
The results of the census at three different factories are summarized in Table 3. The striking feature is the comparatively large proportion of the workers who admit to some sort of injury on the day of the census-6-16 per cent. of the number questioned-and the relatively small proportion of the injured workers who attend the surgery. Many of the injuries are doubtless extremely small, e.g. puncture wounds made by swarf, and might therefore be considered unimportant by the worker. To assess the sepsis rate in the wounds, we have calculated the average number of wounds that were presented to the surgery already septic in the 3-month period around each census day, and the last row in Table 3 shows the estimated daily number of such wounds per 100 wounds untreated at the time of injury, derived from the census. If our premises are correct, it appears that the incidence of sepsis in the untreated wounds is unlikely to have been more than 1-2 per cent.

The agreement of the figures from the three factories shown in Table 3 is noteworthy and lends some weight to the results. It must be added, however, that an attempt to repeat the census in a machine shop of a different firm was not so satisfactory; the figures derived from one week's questioning differed widely from those obtained in a subsequent week, though both agreed in revealing a very large number of untreated injuries. It is probable that the discrepancy was due in part to a different interpretation of the term 'cut' in the two weeks, and in part to the fact that the first week, during which the lower incidence was recorded, fell soon after the Christmas holiday, when the shop was not working to capacity.

\section{Discussion}

The implications of the 'sepsis rate' given by the Factory Department must be made clear. The statement that the rate was 27 per cent. for this factory does not mean that sepsis supervened in 27 per cent. of the wounds inflicted in the factory, or even in 27 per cent. of those leading to loss of more than three working days. It means simply that, of the 266 workers put off work more than three days on account of accidents, 73 were put off because of sepsis. In fact, 143 workers had accidents that were not of the sort that could show sepsis; another 63 had serious wounds at risk for sepsis, but they were notified before the sepsis could have developed, and sepsis did develop later in the wounds of eight of them.

A sepsis rate of 27 per cent. is higher than the average for the country, but this does not necessarily mean that an undue proportion of the wounds in this factory developed sepsis. This is one possible explanation, but another might be that the work done was of the sort that is likely to lead to a large number of trivial injuries but to few serious accidents leading to absence from work from the day of injury. To use the figures for the incidence of sepsis to assess the average risk of sepsis to wounds inflicted in the factory demands a knowledge of the total number of wounds that were inflicted, and the proportion of them that were serious. We estimate that about 10 per cent. of the workers injure themselves each day, although, during the whole of 1944 , only 63 of the wounds were severe enough to lead to absence for three days from the day of injury.

We would not lay great stress on the numerical

TABLE 3

RESULTS OF CENSUS OF INJURIES

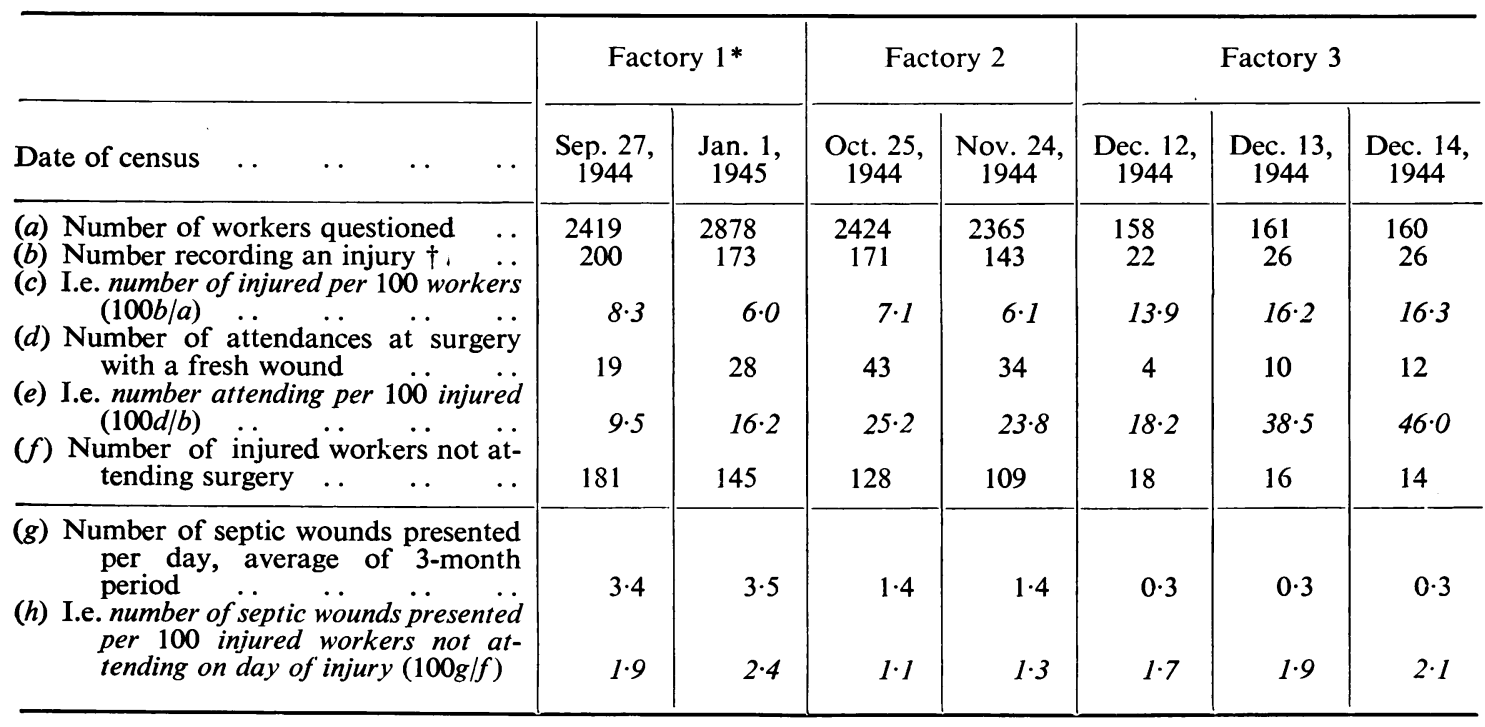

* This is the factory upon which the main report is based, and all the figures from it in this table refer to 'production workers' only. In the other factories, the census included all the workers.

$\dagger$ The figures refer to the number of workers reporting an injury; the average number of injuries per injured worker was $1 \cdot 2$. 
results reported; they are derived from a study of one factory only and, though great care was taken, the methods of obtaining them are certainly open to some criticisms. There can be no doubt, however, on two points: (a) trivial wounds are extremely common in the factory, and $(b)$ the great majority of the septic lesions that are seen in the surgery are septic when first seen, and probably arise from trivial injuries untreated at the time of the accident. Owing to the great number of such injuries, the number of septic wounds, though apparently large, represents but a small proportion of the untreated wounds. Our data suggest that about 5 per cent. of all the injuries treated in the factory surgery on the day of injury develop sepsis, and that the corresponding proportion for the wounds that are not so treated is about 1-2 per cent. In view of the methods by which the figures were obtained, we do not feel justified in drawing any conclusions as to the value of surgery treatment from this small difference. It certainly cannot be used as evidence that the surgery treatment is harmful, because the wounds that are presented to the surgery are on the average likely to be more serious than those that are left untreated, and it is probable that the serious wounds are more liable to become septic than the trivial. In the series observed by Clayton-Cooper and Williams it was, on the whole, the more serious wounds that became septic; and the higher sepsis rate among the large wounds sent to hospital, compared with those treated in the factory surgery, probably reflects the same difference.

That sepsis is not more common among the untreated wound does, however, raise a question as to the importance of the customary exhortation towards early surgery treatment for all wounds. It is evident from our census figures, and from the experience of anyone who has examined the hands of metal workers, that the great majority of small cuts do not become septic, even when untreated. Furthermore, the surgery treatment of all trivial cuts-even if it were possible to induce the workers to attend-would demand a five- to ten-fold increase in surgery staff and accommodation, and would lead to an intolerable loss of working time. Whether it would materially reduce the incidence of sepsis is doubtful. It seems clear that, to some extent, the individual worker must decide whether a small cut requires surgery treatment. We feel that much of the effort spent in the past in exhorting the workers towards early and regular attendance at the surgery with every cut, might be more profitably employed in devising methods of preventing the injuries that allow the entry of bacteria into the tissues, as for instance by designing machines that do not require the worker to handle sharp swarf.
It is not our intention to suggest that the surgery services are redundant; rather would we emphasize that the provision and efficient running of a surgery is not, by itself, enough to solve the problem of industrial sepsis, and that the medical services cannot evade responsibility for the still high incidence of sepsis by the plea that the workers do not attend for treatment sufficiently soon. Sepsis should be regarded as an occupational hazard of the same sort as, for instance, lead poisoning, and its prevention lies not only in the efficient treatment of the workers at greatest risk-those with small wounds -but also in the prevention of those wounds.

\section{Summary and Conclusions}

Analysis of the records for 1944 from one engineering factory employing 7430 workers reveals that there were in all 266 accidents leading to more than three days' absence from work. In 73 cases, the worker was put off on account of sepsis, i.e. the 'sepsis rate' as calculated by the Factory Inspectorate was $27 \cdot 4$ per cent. However, only 143 of the accidents led to wounds at risk for sepsis, and of these 51 per cent. were septic when reported. Ninety per cent. of these septic wounds were septic when first seen at the surgery.

In the same year there were 8101 first attendances at the factory surgery: 7051 with fresh wounds, etc., and 1050 with septic lesions. We can estimate that about 350 of the 7051 fresh wounds probably developed sepsis while under treatment.

Using the data from a census taken to determine the total number of wounds inflicted in the factory, we can estimate that between 6 and 16 per cent. of the workers in the factory suffered an injury on any one day, but that only 9-25 per cent. of the injured workers attended the surgery. We estimate that the incidence of sepsis among the untreated wounds was of the order of 1-2 per cent.

Though the great majority of the cases of sepsis that lead to loss of time occur as a result of the trivial injuries not treated at the time of the accident, the incidence of sepsis in such wounds, in proportion to the very great number that occur, is low, and it does not seem that the elimination of industrial sepsis is to be achieved solely by increasing the aseptic and antiseptic efficiency of the factory surgery. Increasing the proportion of injured workers who attend the surgery might have some effect, but it would be difficult to achieve, and if achieved, it would be uneconomic. Serious attempts must also be made to prevent the occurrence of the trivial injuries that are largely responsible for the sepsis.

\section{Acknowledgments}

We are very grateful to Professor A. Bradford Hill for his help in the planning and analysis of this investigation, and to Dr. S. A. Henry and Dr. J. O. Irwin for their valuable criticism of the work.

The census could not have been carried out without the help from many members of the staff and from the charge-hands in the factories surveyed, and to all of them our thanks are due.

\section{REFERENCES}

Clayton-Cooper, B., and Williams, R. E. O. (1945). Brit. J. industr. Henry, S. A. (1943). Lancet, ii, 721. 